\title{
Marked improvements in glycaemic outcomes following insulin pump therapy initiation in people with type 1 diabetes: a nationwide observational study in Scotland
}

\author{
Anita Jeyam ${ }^{1} \cdot$ Fraser W. Gibb ${ }^{2} \cdot$ John A. McKnight ${ }^{3} \cdot$ Brian Kennon $^{4} \cdot$ Joseph E. O'Reilly $^{1} \cdot$ Thomas M. Caparrotta $^{1}$. \\ Andreas Höhn ${ }^{1}$. Stuart J. McGurnaghan ${ }^{1}$ - Luke A. K. Blackbourn ${ }^{1}$. Sara Hatam ${ }^{1}$ • Rory J. McCrimmon ${ }^{5}$. \\ Graham Leese $^{6} \cdot$ Robert S. Lindsay $^{7}$ - John Petrie ${ }^{7}$. John Chalmers ${ }^{8} \cdot$ Sam Philip $^{9} \cdot$ Sarah H. Wild $^{10} \cdot$ Naveed Sattar $^{7}$. \\ Paul M. McKeigue ${ }^{10}$. Helen M. Colhoun ${ }^{1,11}$. On behalf of the Scottish Diabetes Research Network (SDRN) \\ Epidemiology Group
}

Received: 8 July 2020 / Accepted: 21 December 2020 / Published online: 8 March 2021

(C) The Author(s) 2021

\begin{abstract}
Aims/hypothesis Our aim was to assess the use of continuous subcutaneous insulin infusion (CSII) in people with type 1 diabetes in Scotland and its association with glycaemic control, as measured by $\mathrm{HbA}_{1 \mathrm{c}}$ levels, frequency of diabetic ketoacidosis (DKA) and severe hospitalised hypoglycaemia $(\mathrm{SHH})$, overall and stratified by baseline $\mathrm{HbA}_{1 \mathrm{c}}$.

Methods We included 4684 individuals with type 1 diabetes from the national Scottish register, who commenced CSII between 2004 and 2019. We presented crude within-person differences from baseline $\mathrm{HbA}_{1 \mathrm{c}}$ over time since initiation, crude DKA and SHH event-rates pre-/post-CSII exposure. We then used mixed models to assess the significance of CSII exposure, taking into account: (1) the diffuse nature of the intervention (i.e. structured education often precedes initiation); (2) repeated within-person measurements; and (3) background time-trends occurring pre-intervention.

Results $\mathrm{HbA}_{1 \mathrm{c}}$ decreased after CSII initiation, with a median within-person change of $-5.5 \mathrm{mmol} / \mathrm{mol}(\mathrm{IQR}-12.0,0.0)(-0.5 \%[\mathrm{IQR}$ $-1.1,0.0])$. Within-person changes were most substantial in those with the highest baseline $\mathrm{HbA}_{1 \mathrm{c}}$, with median $-21.0 \mathrm{mmol} / \mathrm{mol}$ $(-30.0,-11.0)(-1.9 \%[-2.7,-1.0])$ change in those with a baseline $>84 \mathrm{mmol} / \mathrm{mol}(9.8 \%)$ within a year of exposure, that was sustained: $-19.0 \mathrm{mmol} / \mathrm{mol}(-27.6,-6.5)(-1.7 \%[-2.5,-0.6])$ at $\geq 5$ years. Statistical significance and magnitude of change were supported by the mixed models results. The crude DKA event-rate was significantly lower in post-CSII person-time compared with pre-CSII person-time: 49.6 events $(95 \%$ CI 46.3, 53.1) per 1000 person-years vs $67.9(64.1,71.9)$; rate ratio from Bayesian mixed models adjusting for preexposure trend: 0.61 (95\% credible interval [CrI] 0.47, 0.77; posterior probability of reduction pp $=1.00)$. The crude overall SHH eventrate in post-CSII vs pre-CSII person-time was also lower: 17.8 events $(95 \%$ CI 15.8, 19.9) per 1000 person-years post-exposure vs 25.8 $(23.5,28.3)$ pre-exposure; rate ratio from Bayesian mixed models adjusting for pre-exposure trend: $0.67(95 \% \mathrm{CrI} 0.45,1.01 ; \mathrm{pp}=0.97)$. Conclusions/interpretation CSII therapy was associated with marked falls in $\mathrm{HbA}_{1 \mathrm{c}}$ especially in those with high baseline $\mathrm{HbA}_{1 \mathrm{c}}$. CSII was independently associated with reduced DKA and SHH rates. CSII appears to be an effective option for intensive insulin therapy in people with diabetes for improving suboptimal glycaemic control.
\end{abstract}

Anita Jeyam

anita.jeyam@igmm.ed.ac.uk

1 MRC Institute of Genetic and Molecular Medicine, University of Edinburgh, Edinburgh, UK

2 Royal Infirmary of Edinburgh, Edinburgh Centre for Endocrinology and Diabetes, Edinburgh, UK

3 Western General Hospital, NHS Lothian, Edinburgh, UK

4 Queen Elizabeth University Hospital, Glasgow, UK

5 Division of Molecular and Clinical Medicine, University of Dundee, Dundee, UK
6 Ninewells Hospital, Dundee, UK

7 Institute of Cardiovascular and Medical Sciences, University of Glasgow, Glasgow, UK

8 Diabetes Centre, Victoria Hospital, Kirkcaldy, UK

9 Grampian Diabetes Research Unit, Diabetes Centre, Aberdeen Royal Infirmary, Aberdeen, UK

10 Usher Institute of Population Health Sciences and Informatics, Centre for Population Health Sciences, School of Molecular, Genetic and Population Health Sciences, University of Edinburgh, Edinburgh, UK

11 Public Health, NHS Fife, Kirkcaldy, UK 


\section{Research in context}

\section{What is already known about this subject?}

- Continuous subcutaneous insulin infusion (CSII) is associated with reductions in $\mathrm{HbA}_{1 \mathrm{c}}$ in people with type 1 diabetes. Previous observational studies have generally been local, had a small sample size or a short follow-up time, or been paediatric-focused

- $\quad$ CSII has a conflicting history of association with diabetic ketoacidosis (DKA)

- Several studies have shown CSII to be associated with a reduction in hypoglycaemia

\section{What is the key question?}

- In people with type 1 diabetes from a nationwide Scottish population-based registry using CSII, how do $\mathrm{HbA}_{1 c}$ levels, DKA rates and severe hospitalised hypoglycaemia $(\mathrm{SHH})$ rates evolve following CSIl initiation, overall and by sociodemographic strata?

What are the new findings?

- $\quad$ CSII is associated with long-term improvements in $\mathrm{HbA}_{1 c}$ in both adults and children. Improvements are most marked among those with highest starting $\mathrm{HbA}_{1 c}$

- $\quad$ CSII is associated with a reduced rate in DKA overall, although directions of associations vary across age bands; it is also associated with a reduced rate in $\mathrm{SHH}$ overall

- CSII-related associations are not worse in those from more deprived areas, although prevalence of use remains lower in the most vs less deprived areas

\section{How might this impact on clinical practice in the foreseeable future?}

- CSII shows potential to further improve glycaemic control in the Scottish type 1 diabetes population and is a promising option for intensive insulin therapy in those with suboptimal glycaemic control

Keywords Diabetes mellitus type $1 \cdot \mathrm{HbA}_{1 \mathrm{c}} \cdot \mathrm{Hypoglycaemia} \cdot$ Insulin pump $\cdot$ Ketoacidosis

$\begin{array}{ll}\text { Abbreviations } & \\ \text { CGM } & \text { Continuous glucose monitoring } \\ \text { CrI } & \text { Credible interval } \\ \text { CSII } & \text { Continuous subcutaneous insulin infusion } \\ \text { DKA } & \text { Diabetic ketoacidosis } \\ \text { MDI } & \text { Multiple daily injections } \\ \text { NHS } & \text { National Health Service } \\ \text { NICE } & \text { National Institute for Health and Care } \\ & \text { Excellence } \\ \text { pp } & \text { Posterior probability } \\ \text { SCI-Diabetes } & \text { Scottish Care Information-Diabetes } \\ \text { SHH } & \text { Severe hospitalised hypoglycaemia } \\ \text { SIMD } & \text { Scottish Index of Multiple Deprivation }\end{array}$

\section{Introduction}

As continuous subcutaneous insulin infusion (CSII) usage to aid diabetes management becomes more widespread, there is still uncertainty regarding its effectiveness and safety. RCTs reported small improvements in $\mathrm{HbA}_{1 \mathrm{c}}$
post-CSII initiation; before/after studies suggested larger effects [1]. Several studies reported a reduction in severe hypoglycaemia rates [1-3]. The effect of CSII on diabetic ketoacidosis (DKA) is unclear as studies conflict in direction of effect reported [2-4].

Criteria for CSII initiation differ across countries [5]. CSII therapy initiation in Scotland follows criteria set by the National Institute for Health and Care Excellence (NICE) guidelines [6], Scottish Government policy and individual National Health Service (NHS) health board budget allocation decisions. A recent study [7] examined the effect of CSII therapy on $\mathrm{HbA}_{1 \mathrm{c}}$ among people with type 1 diabetes in the Scottish health board Lothian and found a significant decrease in $\mathrm{HbA}_{1 \mathrm{c}}$ following CSII initiation, particularly among those with suboptimal glycaemic control. In this paper, we widen the scope of that analysis by focusing on CSII therapy initiation in people with type 1 diabetes throughout Scotland.

Our aim was to: (1) describe the current prevalence of everCSII use; and (2) assess the effect of CSII therapy on glycaemic control as measured by $\mathrm{HbA}_{1 \mathrm{c}}$, DKA and severe hospitalised hypoglycaemia ( $\mathrm{SHH})$. We furthermore explored 
differences in CSII therapy effect across baseline $\mathrm{HbA}_{1 \mathrm{c}}$ bands and sociodemographic strata (age band at CSII initiation, sex, area-level deprivation).

\section{Methods}

Ethics permission Data and data linkage were originally set up with approval from the Scottish A Research Ethics Committee (ref 11/AL/0225), Caldicott Guardians and the Privacy Advisory Committee (PAC - ref. 33/11), now running with approval from the Public Benefit and Privacy Panel for Health and Social Care (PBPP - reference 1617-0147).

Data sources We used anonymised data from the Scottish Care Information - Diabetes Collaboration database (SCIDiabetes), which holds extensive electronic healthcare records of $>99 \%$ of people with diabetes in Scotland, both adults and children, since 2004. SCI-Diabetes covers extensive clinical and prescription information including CSII start dates. These data are linked to hospital admissions records and mortality data from the Information Services Division (ISD) of NHS Scotland and the National Records of Scotland. SCIDiabetes and associated linkage have previously been described $[8,9]$.

Study population Among those alive and observable with type 1 diabetes in SCI-Diabetes at any time from 2004 to 2019, we analysed glycaemic outcomes among those who initiated CSII therapy before June 2019. Type of diabetes was assessed from our validated algorithm [10]. Individuals contributed person-time from the latest of: 1 January 2004, first observability date (based on prescribing, hospital admission or clinical measurements) or date of diabetes diagnosis. Person-time was censored at the earliest of: 12 December 2019 (administrative censoring), date of death, last date of observability, first stop date of CSII (if no restart within a year). Person-time was additionally censored when starting flash monitoring or continuous glucose monitoring (CGM) device after CSII to isolate the effect of CSII initiation from that of other technologies (see electronic supplementary material [ESM] Methods).

Exposure, outcomes and covariates Exposure of interest is CSII therapy. Since CSII users in Scotland are selected based on criteria that are not measurable in our data (e.g. motivation, perceived ability to use a pump), we chose to conduct analyses within CSII users. Glycaemic outcomes were compared among CSII users before and after CSII initiation, using data up to a maximum of 5 years prior to initiation. We used a 1:1 non-user control group, matched by age, sex and diabetes duration (ESM Methods) to check for any trend occurring in $\mathrm{HbA}_{1 \mathrm{c}}$ among non-users in similar calendar time, and to inform results obtained in adolescents given the deterioration in glycaemic control in this age group [2, 11].

We defined DKA and SHH as any hospital admission or death involving the ICD-10 (http://apps.who.int/ classifications/icd10/browse/2016/en) codes detailed in ESM Methods. Each unique hospital admission was considered as an event. Person-time for DKA/SHH analyses was censored at the last date of available data for hospital admissions: 30 April 2019.

Demographic and clinical information were obtained from SCI-Diabetes. For clinical covariates, baseline values were defined as median value over the 2 years prior to device initiation for continuous variables or the most clinically severe status over this time-window for categorical variables. We used Scottish Index of Multiple Deprivation (SIMD) quintiles as a measure of area-level deprivation, quintile (Q)1 being the most deprived. Age at CSII initiation (years) was categorised into six age bands: $<13, \geq 13-\leq 18, \geq 19-\leq 24, \geq 25-\leq 44$, $\geq 45-\leq 64$ and $>64$; and baseline $\mathrm{HbA}_{1 \mathrm{c}}$ levels ( $\mathrm{mmol} / \mathrm{mol}$ ) into five groups, representative of different glycaemic control levels: $<54$ (7.1\%), $\geq 54-\leq 68(8.4 \%), \geq 69-\leq 74(8.5-8.9 \%)$, $\geq 75-\leq 84(9.0-9.8 \%)$ and $>84$.

Statistical analysis All analyses were conducted using R version 3.6.0-64 bit [12] at significance level $p=0.05$. Missing data were not imputed.

We presented the crude prevalence of ever-CSII users overall and stratified by baseline variable. In order to study the effect of CSII on $\mathrm{HbA}_{1 \mathrm{c}}$, we divided observation time into blocks of 1 year periods before and after CSII initiation, centred on the date of CSII initiation [7], and compared the median $\mathrm{HbA}_{1 \mathrm{c}}$ value of each individual in each time-block. $\mathrm{HbA}_{1 \mathrm{c}}$ levels and absolute within-person differences with respect to baseline were described before and after CSII initiation, overall and stratified by age, baseline $\mathrm{HbA}_{1 \mathrm{c}}$, sex, SIMD and prior flash monitoring/CGM use. Significance of within-person differences were assessed at each time point after CSII initiation, using a one-sided Wilcoxon signedrank test; $p$ values were adjusted for multiple comparison using Bonferroni's correction.

Crude pre-/post-exposure changes can under/overestimate an intervention's effect when there is a pre-intervention trend in the outcome which is not taken into account. Logtransformed $\mathrm{HbA}_{1 \mathrm{c}}$ was modelled using linear mixed models [13] to assess whether changes were similar and statistically significant when accounting for pre-exposure trajectory [14]. CSII initiation in Scotland is a diffuse intervention. It is typically preceded by more frequent clinical encounters and attendance at a structured education programme, such as Dose Adjustment For Normal Eating (DAFNE), in the 2 years prior to initiation. In modelling the impact of CSII, we wished to ensure that any within-person trend over calendar time unrelated to CSII could be accounted for in the analysis. In order to 
evaluate this trend, the $\mathrm{HbA}_{1 \mathrm{c}}$ measurements within the 2 years prior to CSII initiation were excluded since they are related to CSII (see ESM Methods for more details).

Therefore the models estimated the 'full package' effect of CSII plus related prior interventions in the 2 year run-up to CSII as they reflect change in $\mathrm{HbA}_{1 \mathrm{c}}$ from before the package started to after it was fully implemented. Models were fitted using R package $n l m e$ version 3.1-143 [15]. Differential effect of CSII by sociodemographic variable was tested using interaction terms (ESM Methods). Where significant, stratified model results were presented.

Due to the sparse nature of DKA/SHH events, we described the crude event-rate before and after CSII, by dividing the number of events observed by the total number of person-years under observation pre- or post-CSII exposure. To account for repeated occurrence of events within individuals and the background pre-package time-trend, we used generalised linear mixed models with a Poisson likelihood with a random intercept, excluding the 2 years prior to initiation. CSII exposure was included as a binary, time-varying covariate (non-exposed/exposed). All models were adjusted for sex, age and diabetes duration at CSII initiation, baseline $\mathrm{HbA}_{1 \mathrm{c}}$ and pre-package time-trend. Classical likelihood inference for this model relies on approximations of intractable integrals, therefore we used a Bayesian approach [16]. We presented the back-transformed posterior mean (rate ratio) and associated $95 \%$ credible intervals (CrI), alongside the posterior probability (pp) of the $\beta$ coefficient associated to CSII exposure being positive or negative in order to quantify the uncertainty around the direction of the effect [17]. Models were implemented using R package rstan version 2.19.3 (see ESM Methods for more details).

\section{Results}

Prevalence A total of 4941 people ever used CSII between 2004 and the end of 2019. The crude prevalence of ever-CSII users has increased over the past decade from $0.1 \%$ in 2004 to $15.1 \%$ in 2019. Disparities in CSII usage by the end of 2019 were observed across sociodemographic strata (ESM Fig. 1). Prevalence of ever-CSII users was highest in younger age bands and decreased with age ( $48.1 \%$ in the under 13 age band vs $4.3 \%$ in those aged 65 years or older), higher in female $(19.9 \%)$ vs male participants $(11.3 \%)$ and twice as high among those living in the least vs the most deprived areas (19.6\% in SIMD Q5 vs $10.4 \%$ in Q1).

Baseline cohort characteristics We analysed glycaemic outcomes in 4684 CSII users who initiated CSII before June 2019. Their baseline characteristics are described in Table 1, alongside those of the non-user sample. Their median overall observation time was 12.4 years; median post- exposure follow-up time was 3.6 years; and 3108 individuals started using flash monitoring/CGM after starting CSII.

HbA1c levels $\mathrm{HbA}_{1 \mathrm{c}}$ decreased after CSII initiation (ESM Fig.2) from median $66.0 \mathrm{mmol} / \mathrm{mol}(\mathrm{IQR} 58.0,74.0)(8.2 \%$ [IQR 7.5, 8.9]) in the year before initiation to $60.0 \mathrm{mmol} / \mathrm{l}$ $(54.0,67.0)(7.6 \%[7.1,8.3])$ during the first year of CSII exposure and $63.0(56.0,71.0)(7.9 \%[7.3,8.6])$ after $\geq 5$ years. $\mathrm{HbA}_{1 \mathrm{c}}$ levels started decreasing around 2 years prior to CSII initiation, and levels were stable in the preceding years.

Crude within-person differences in $\mathrm{HbA}_{1 \mathrm{c}}$ levels with respect to baseline $\mathrm{HbA}_{1 \mathrm{c}}$ are illustrated in Fig. 1 overall and stratified by age at CSII initiation, sex, SIMD quintile and baseline $\mathrm{HbA}_{1 \mathrm{c}}$. At an individual level, there was a reduction in $\mathrm{HbA}_{1 \mathrm{c}}$ levels post-CSII initiation sustained through time (ESM Table 1): median $-5.5 \mathrm{mmol} / \mathrm{mol}$ (IQR $-12.0,0.0$ ) $(-0.5 \%$ [IQR $-1.1,0.0])(p<0.01)$ within the first year postexposure and $-5.0 \mathrm{mmol} / \mathrm{mol}(-12.5,2.8)(-0.5 \%[-1.1,0.3])$ $(p<0.01)$ for $\geq 5$ years. Mixed-model results showed no timetrend trajectory of $\mathrm{HbA}_{1 \mathrm{c}}$ prior to CSII-package initiation. CSII initiation was associated with a significant and sustained long-term reduction in $\mathrm{HbA}_{1 \mathrm{c}}$ levels compared with prepackage levels (Table 2). The estimated fold-change was 0.88 overall. For someone with pre-package $\mathrm{HbA}_{1 \mathrm{c}}$ levels of $69 \mathrm{mmol} / \mathrm{mol}(8.5 \%)$, this would correspond to a change of around $-8 \mathrm{mmol} / \mathrm{mol}(-0.7 \%)$.

Within-person $\mathrm{HbA}_{1 \mathrm{c}}$ remained stable in the calendar time following pump initiation in the non-user group, with a within-person change of $0.0 \mathrm{mmol} / \mathrm{mol}$ (IQR $-6.0,5.5$ ) $(0.0 \%[-0.5,0.5])$ in year 1 to $-1.0 \mathrm{mmol} / \mathrm{mol}(-10.0,9.0)$ $(-0.1 \%[-0.9,0.8])$ at $\geq 5$ years (ESM Fig. 3 ).

CSII exposure effect varied significantly across baseline $\mathrm{HbA}_{1 \mathrm{c}}$, age and sex, and prior flash monitoring/CGM use ( $p_{\text {interaction }}<0.01$ for all), but not across SIMD ( $p_{\text {interaction }}=0.25$ ).

Reductions in $\mathrm{HbA}_{1 \mathrm{c}}$ from baseline were observed in all bands $\geq 54 \mathrm{mmol} / \mathrm{mol}$ (7.1\%) (Fig. 1, ESM Table 1), whereas $\mathrm{HbA}_{1 \mathrm{c}}$ levels increased slightly in the $<54 \mathrm{mmol} / \mathrm{mol}$ band. Reductions were significant and sustained through time, with the greatest fall corresponding to the highest baseline $\mathrm{HbA}_{1 \mathrm{c}}$ bands: $-21.0 \mathrm{mmol} / \mathrm{mol}$ (IQR $-30.0,-11.0)(-1.9 \%$ [IQR $-2.7,-1.0])(p<0.01)$ in the first year post-exposure and $-19.0 \mathrm{mmol} / \mathrm{mol}(-27.6,-6.5)(-1.7 \%[-2.5,-0.6])$ at $\geq 5$ years in those with baseline $\mathrm{HbA}_{1 \mathrm{c}}>84 \mathrm{mmol} / \mathrm{mol}$ $(9.8 \%)(p<0.01)$. Results from the mixed models were similar (Table 2), with an estimated 0.8-fold-change sustained through time in this group.

Within-person reductions in $\mathrm{HbA}_{1 \mathrm{c}}$ were slightly higher in female than male participants (ESM Tables 2, 3).

Across age, within-person $\mathrm{HbA}_{1 \mathrm{c}}$ reductions were highest among those aged 19-24. Significant reductions were observed in all age bands and sustained through time except in the 13-18 years group. In these adolescents, after an initial decrease, there was no significant 
Table 1 Baseline characteristics of CSII users and matched non-users for analyses of glycaemic outcomes

\begin{tabular}{|c|c|c|c|c|}
\hline \multirow[b]{2}{*}{ Variable } & \multicolumn{2}{|l|}{ CSII users $(N=4684)$} & \multicolumn{2}{|c|}{ Matched non-users $(N=4141)$} \\
\hline & $n(\%)$ or median (IQR) & Missingness (\%) & $n(\%)$ or median (IQR) & Missingness (\%) \\
\hline Sex, female & $2749(58.7)$ & 0.0 & $2438(58.9)$ & 0.0 \\
\hline Age at initiation & $27.5(12.6,41.3)$ & 0.0 & $27.9(13.5,41.1)$ & 0.0 \\
\hline Diabetes duration at initiation & $11.4(3.0,22.9)$ & 0.0 & $12.0(3.3,22.9)$ & 0.0 \\
\hline $\mathrm{HbA}_{1 \mathrm{c}}$ band at baseline & & 3.8 & & 11.9 \\
\hline$<54 \mathrm{mmol} / \mathrm{mol}(<7.1 \%)$ & $529(11.7)$ & & $377(10.3)$ & \\
\hline $54-68 \mathrm{mmol} / \mathrm{mol}(7.1-8.4 \%)$ & $2117(47.0)$ & & $1264(34.7)$ & \\
\hline 69-74 mmol/mol (8.5-8.9\%) & $713(15.8)$ & & $563(15.4)$ & \\
\hline $75-84 \mathrm{mmol} / \mathrm{mol}(9.0-9.8 \%)$ & $673(14.9)$ & & $682(18.7)$ & \\
\hline$>84 \mathrm{mmol} / \mathrm{mol}(>9.8 \%)$ & $474(10.5)$ & & $761(20.9)$ & \\
\hline$n \mathrm{HbA}_{1 \mathrm{c}}$ measurements per individual & $20.0(14.0,28.0)$ & 0.0 & $25.0(15.0,36.0)$ & 0.0 \\
\hline BMI, $\mathrm{kg} / \mathrm{m}^{2}$ & $23.7(19.4,27.3)$ & 5.8 & $23.9(19.9,27.9)$ & 14.7 \\
\hline Triacylglycerols, mmol/1 & $1.0(0.8,1.4)$ & 47.0 & $1.1(0.8,1.6)$ & 51.2 \\
\hline Total cholesterol, mmol/1 & $4.6(4.0,5.2)$ & 34.3 & $4.7(4.1,5.3)$ & 40.0 \\
\hline HDL-cholesterol, mmol/1 & $1.5(1.3,1.8)$ & 40.6 & $1.5(1.2,1.8)$ & 46.4 \\
\hline LDL-cholesterol, mmol/1 & $2.5(2.0,3.0)$ & 63.3 & $2.5(2.0,3.0)$ & 67.6 \\
\hline Systolic BP, mmHg & $123.5(114.0,133.0)$ & 22.0 & $122.0(113.0,132.0)$ & 25.8 \\
\hline Diastolic BP, mmHg & $73.0(67.5,79.5)$ & 22.0 & $73.0(67.0,79.0)$ & 24.8 \\
\hline CKD-EPI eGFR, $\mathrm{ml} \mathrm{min}^{-1}[1.73 \mathrm{~m}]^{-2}$ & & 29.9 & & 35.1 \\
\hline$<15$ & $15(0.5)$ & & $32(1.2)$ & \\
\hline $15-30$ & $18(0.5)$ & & $17(0.6)$ & \\
\hline $30-60$ & $73(2.2)$ & & $75(2.8)$ & \\
\hline $60-90$ & $647(19.7)$ & & $479(17.8)$ & \\
\hline$\geq 90$ & $2531(77.1)$ & & $2086(77.6)$ & \\
\hline Albuminuric status: micro/macro albuminuria & $618(21.5)$ & 38.5 & $541(25.6)$ & 49.0 \\
\hline SIMD quintile & & 7.9 & & 8.1 \\
\hline Q1 (most deprived) & $618(14.3)$ & & $933(24.5)$ & \\
\hline Q2 & $787(18.2)$ & & $812(21.3)$ & \\
\hline Q3 & $933(21.6)$ & & $793(20.8)$ & \\
\hline Q4 & $944(21.9)$ & & $678(17.8)$ & \\
\hline Q5 (least deprived) & $1032(23.9)$ & & $588(15.5)$ & \\
\hline Ever prior DKA admission & $1011(22.0)$ & 1.8 & $1072(27.5)$ & 5.7 \\
\hline Ever prior hypoglycaemia admission & $497(10.8)$ & 1.8 & $387(9.9)$ & 5.7 \\
\hline Prior FM/CGM usage & $389(8.3)$ & 0.0 & - & - \\
\hline
\end{tabular}

FM, flash monitoring

difference from baseline beyond the second year. Model estimates showed marginally higher values compared with the expected pre-package $\mathrm{HbA}_{1 \mathrm{c}}$ trajectory (ESM Tables 4, 5). When compared with the matched controls (ESM Fig. 4), $\mathrm{HbA}_{1 \mathrm{c}}$ was lower in the adolescent group in users both before and after CSII initiation. In nonusers, $\mathrm{HbA}_{1 \mathrm{c}}$ rose from baseline levels until 3 years post-index: median within-person change from baseline $5.0 \mathrm{mmol} / \mathrm{mol}$ (IQR $-6.0,16.5)(0.5 \%$ [IQR $0.5,1.5])$ vs $-0.0 \mathrm{mmol} / \mathrm{mol}$ $(-8.4,8.0)(0.0 \%[-0.8,0.7])$ in non-users vs users respectively $(p<0.01)$. Levels returned close to baseline in subsequent years.
Within-person reductions in $\mathrm{HbA}_{1 \mathrm{c}}$ did not vary across SIMD (ESM Table 6). They were slightly higher in those with prior flash monitoring/CGM use (ESM Tables 7, 8).

DKA and SHH events Overall, 1187 DKA events were observed over $17,479.8$ person-years prior to CSII initiation, and 827 DKA events over 16,675.0 person-years after initiation. The crude DKA rate increased prior to package initiation and started decreasing thereafter (ESM Fig. 5, ESM Table 9).

The crude DKA event-rate was significantly lower in CSIIexposed person-time than in non-exposed person-time: 49.6 
events $(95 \%$ CI 46.3, 53.1) per 1000 person-years vs 67.9 (64.1, 71.9).

The Bayesian mixed models confirmed the increasing trend in DKA frequency prior to package initiation and demonstrated that CSII exposure was associated with a reduction in DKA rate compared with the counterfactual: rate ratio $0.61(95 \% \mathrm{CrI} 0.47,0.77)$, with pp of $\beta<0$ (i.e. reduction) $=$ 1.00 (ESM Table 10). Hence, we can be very confident that there is a true association.

Crude DKA rates by CSII exposure status, stratified by baseline $\mathrm{HbA}_{1 \mathrm{c}}$ band, sex, age and SIMD are described in Fig. 2.

Stratified by baseline $\mathrm{HbA}_{1 \mathrm{c}}$ band, significant reductions in DKA rates were observed post-exposure in the $54-68 \mathrm{mmol} /$ $\mathrm{mol}$ and $\geq 75 \mathrm{mmol} / \mathrm{mol}$ groups (ESM Table 11). Model results were consistent with an association of CSII exposure with a reduction in DKA rate when controlling for preintervention trend in the 54-68 $\mathrm{mmol} / \mathrm{mol}$ and the $>84 \mathrm{mmol} / \mathrm{mol}$ bands (ESM Table 12 ).

Crude DKA rates were higher in female than male participants (ESM Table 13) but lower in exposed person-time in both groups. Model results were similar, with CSII being associated with a rate reduction in both groups (ESM Table 14).

Across age band, crude rates were lower in CSII-exposed time, except in the 13-18 years and 45-64 years groups (Fig. 2, ESM Table 15). Model results were generally similar (ESM Table 16). Data were too sparse in the 65 years and older group to draw meaningful conclusions. DKA rates in the 13-18 years group were higher in non-users than users both before and after pump start-date. The crude event-rate in nonusers increased from 157.5 (95\% CI 139.9, 176.7) pre-index to $244.4(224.7,265.4)$ in the post-index person-time, i.e. as the adolescents get older (ESM Fig. 6). The post-/pre-index increase was similar to that observed in pump users: crude rate ratio $1.55(95 \%$ CI $1.35,1.79)$ in non-users vs rate ratio 1.43 $(1.16,1.77)$ in users.

Higher deprivation levels were associated with increased crude DKA rates. Rates were lower in exposed vs unexposed person-time, though the difference was not always significant (Fig. 2, ESM Table 17). Model results were similar (ESM Table 18).

Crude DKA rates were lower in CSII-exposed time in both those with and without prior flash monitoring/CGM use. Sample size was too low for meaningful inference in the prior flash monitoring/CGM group (ESM Tables 19, 20).

Overall, $451 \mathrm{SHH}$ events were observed in the unexposed person-years, and 296 events in the exposed person-years. The crude $\mathrm{SHH}$ rate increased in all years prior to CSII initiation. The crude SHH event-rate was lower in CSII-exposed than non-exposed person-time: 17.8 events per 1000 person-years (95\% CI 15.8, 19.9) vs 25.8 (23.5, 28.3). Model estimates from the Bayesian mixed models were consistent with an association of CSII with a reduction in $\mathrm{SHH}$ rates compared with pre-package levels: rate ratio 0.67 (95\% CrI 0.45, 1.01), $\mathrm{pp}=0.97$ (ESM Table 21). Hence, we have good confidence that there is a true association. Event numbers were too low to perform stratified analyses.

\section{Discussion}

We investigated the current prevalence of CSII usage among the Scottish population with type 1 diabetes. We studied the association of CSII therapy with $\mathrm{HbA}_{1 \mathrm{c}}$ levels, DKA and $\mathrm{SHH}$ event-rates. Prevalence of CSII usage is relatively low, but growing, and varies substantially across sociodemographic strata. CSII therapy was associated with a reduction in $\mathrm{HbA}_{1 \mathrm{c}}$, which was sustained through time for at least 5 years. The greatest reductions were seen in those with the highest baseline $\mathrm{HbA}_{1 \mathrm{c}}$ levels. Effects of exposure did not vary across SIMD quintiles (but CSII prevalence did), while sustained reductions of varying magnitude were seen across sex and age bands, apart from in adolescents. Comparisons with adolescent non-users nonetheless suggested an improvement with CSII in this group. CSII was associated with an overall reduction in DKA rate but the magnitude and direction of effect varied across sociodemographic strata. CSII was associated with an overall reduction in $\mathrm{SHH}$ rate.

CSII therapy is generally not funded out-of-pocket in Scotland. There has been a significant increase in CSII provision across the country in the last 8 years in line with a nationwide effort to support the availability of CSII. Variability of usage across sociodemographic strata followed similar patterns to other countries: van den Boom et al. [18] reported higher usage within younger age bands in the Diabetes Patienten Verlaufsdokumentation (DPV) cohort. The National Diabetes Insulin Pump Audit [19] (England, Wales) 2017-2018 reported a higher pump-use prevalence in women and in those from less deprived areas. Findings from a qualitative study by Scott et al. [20] highlighting higher access barriers to intensive insulin regimen (including CSII therapy) for people from lower socioeconomic groups are reflected in our observation that CSII prevalence is lower among the most deprived.

Within-person changes observed in our national study following CSII initiation were comparable in direction and magnitude to those reported regionally in NHS Lothian [7]. We found the CSII therapy package to be independently associated with a significant fall in $\mathrm{HbA}_{1 \mathrm{c}}$. Magnitude and direction of estimated changes are similar to those reported in before/after studies of patients switching from multiple daily injections (MDI) to CSII in Pickup and Sutton's meta-analysis [1]: $-0.72 \%(-7.9 \mathrm{mmol} / \mathrm{mol})$. Our findings are in line with those from other local-scale UK studies which reported improvements in glycaemic control following CSII initiation to be sustained at least up to 5 to 6 years $[7,21,22]$. While 
a

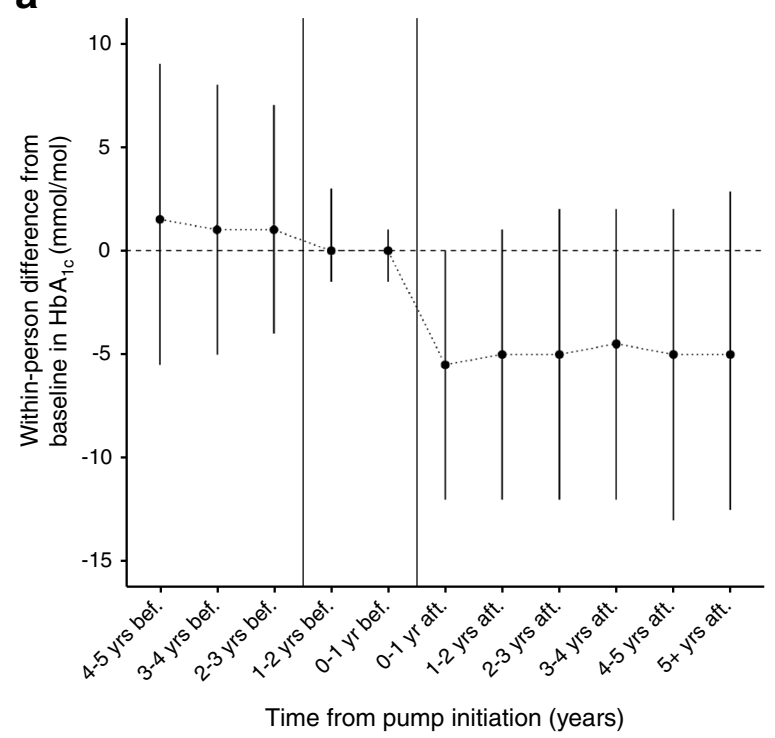

C

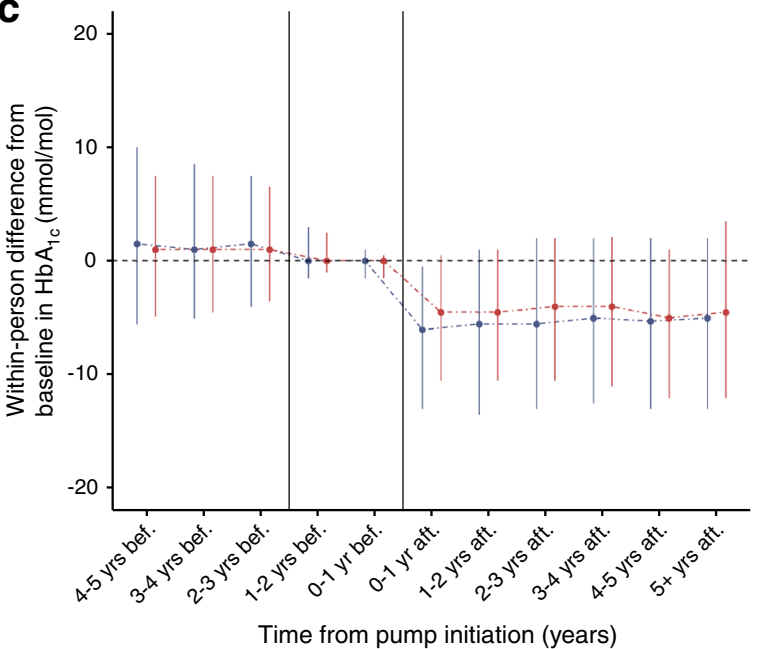

Sex 'Female ' Male

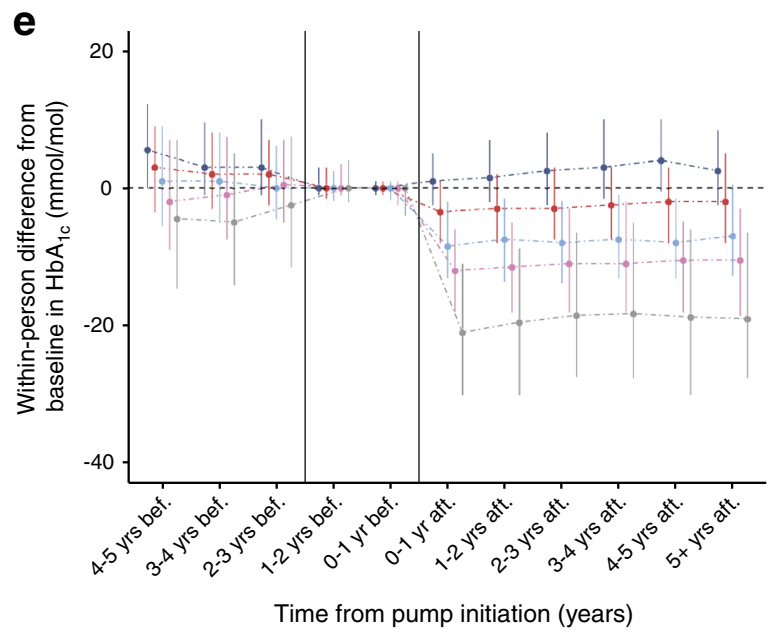

Baseline $\mathrm{HbA}_{1 \mathrm{c}}$ band (mmol/mol) $<54 \quad 54-68 \quad 69-74 \quad 75-84>84$ b

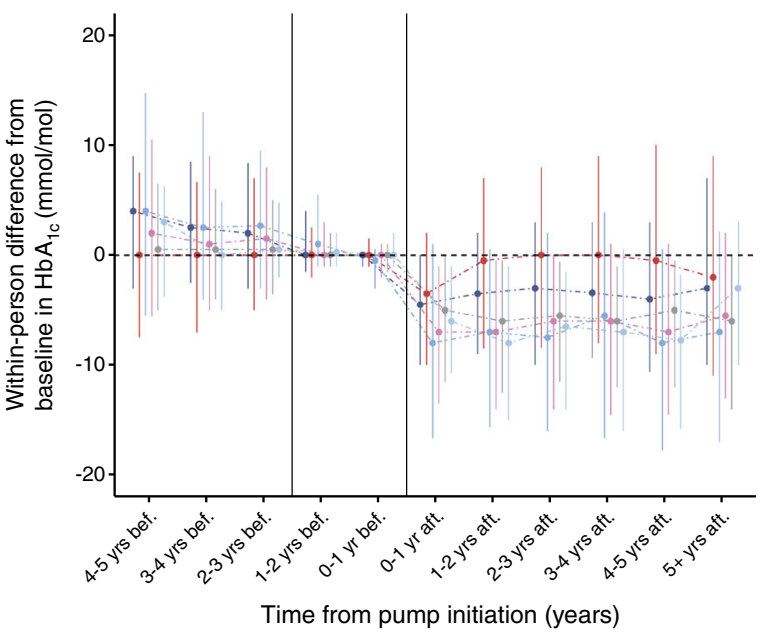

Age at pump initiation (years) \begin{tabular}{llll}
$<13$ & $19-24$ & $45-64$ \\
\hdashline & $13-18$ & $25-44$ & $>64$
\end{tabular}

d

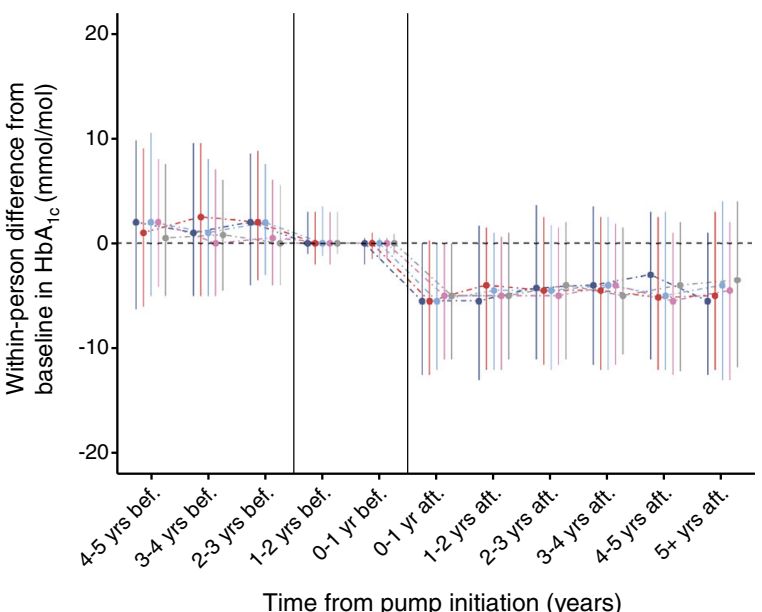

SIMD quintile Q1 (most deprived) Q2 Q3 Q4 Q5 (least deprived)

f

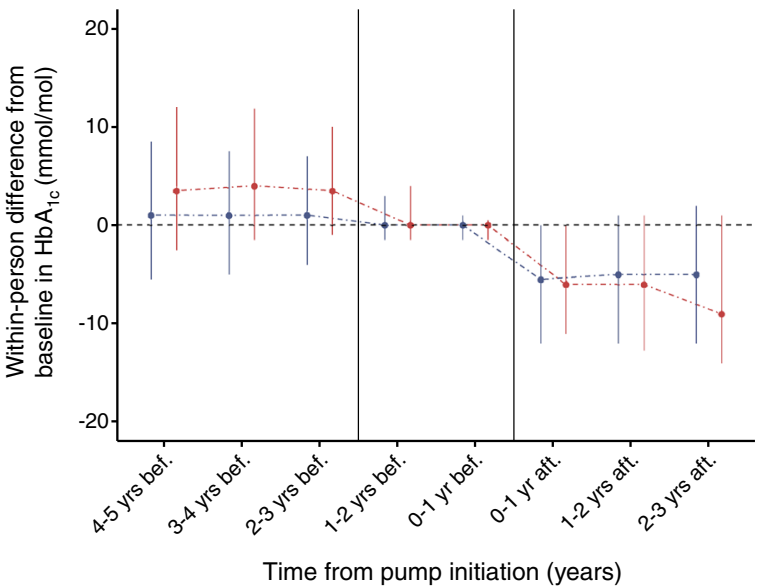

Prior Flash Monitor usage No Yes 
Fig. 1 Crude within-person differences in $\mathrm{HbA}_{1 \mathrm{c}}(\mathrm{mmol} / \mathrm{mol})$ with respect to individual median over the 2 years prior to CSII initiation, by time from CSII initiation (years). (a) Overall, (b) stratified by age band at CSII initiation, (c) sex, (d) SIMD quintile, (e) baseline $\mathrm{HbA}_{1 \mathrm{c}}$ band and (f) prior flash monitoring/CGM usage. Results for prior flash monitoring/ CGM usage are presented up to $2-3$ years post-CSII initiation as $n<20$ in subsequent years for prior flash monitoring/CGM group. Data are median (IQR). Abbreviations: aft., after; bef., before; yr/yrs. year/years

diabetes care in Scotland has improved in the past decade, the stability of $\mathrm{HbA}_{1 \mathrm{c}}$ in the matched non-user sample supports conclusions that observed reductions among pump users are associated with CSII-package and not explained by the secular trend of $\mathrm{HbA}_{1 \mathrm{c}}$ improvement.

In line with previous findings, those with the highest baseline $\mathrm{HbA}_{1 \mathrm{c}}$ benefited most from CSII. NHS Lothian reported a $-22.2 \mathrm{mmol} / \mathrm{mol}$ change in those starting with $\mathrm{HbA}_{1 \mathrm{c}} \geq$ $85 \mathrm{mmol} / \mathrm{mol}$ and the meta-analysis showed a mean difference (MDI vs CSII) greater than $16 \mathrm{mmol} / \mathrm{mol}$ for those with baseline $\mathrm{HbA}_{1 \mathrm{c}} \geq 80 \mathrm{mmol} / \mathrm{mol}[1,23]$. Hence, CSII helps individuals transition from higher to lower complication-risk $\mathrm{HbA}_{1 \mathrm{c}}$ groups. The slight increase in $\mathrm{HbA}_{1 \mathrm{c}}$ in those with baseline levels $<54 \mathrm{mmol} / \mathrm{mol}$ is unsurprising as it is likely that this group would have been prescribed CSII to reduce hypoglycaemia.

Differences observed across sex strata were similar to previous findings [7, 24].

Patterns in $\mathrm{HbA}_{1 \mathrm{c}}$ among those starting a pump in their teenage years were similar to those described by Johnson et al. in their long-term paediatric CSII outcome study (median age 11.5 years) [2]. In their study, after an initial decrease, $\mathrm{HbA}_{1 \mathrm{c}}$ started increasing but remained lower than levels of matched control participants on MDI, and differences remained significant for 7 years. Our study's matched differences stopped being significant after 4 years, likely due to our group including older individuals, who, after adolescence, transition into a phase of more stable glycaemic control, whereas participants in the study by Johnson et al. were censored when they transitioned to adult services. Related to this, the higher reductions among the 19-24 years age band are likely due to a combination of glycaemic control tending to stabilise at lower levels beyond adolescence, and CSII use.

Although the sample size was small, we found that CSII was beneficial in those initiating CSII after prior flash monitoring/CGM usage.

We found CSII to be associated with a reduced overall DKA rate, whereas previous findings have been conflicting. A meta-analysis [25] suggested that CSII was associated with higher DKA rates in older studies (before 1993). Pickup and Keen [26] noted that modifiable factors such as patient/ healthcare provider inexperience can increase the likelihood of DKA around the beginning of CSII use, as ketosis occurs rapidly following insulin interruption due to use of rapidacting insulin in CSII devices [4], but we found no increase of crude DKA rates within the first year of usage.

More recent studies have been inconclusive. Some paediatric studies reported decreases, and others reported increases [2-4, 27]. Thomas et al. [28] identified CSII as a predictor of DKA in adults from the FinnDiane cohort. Different followup times, DKA definitions (e.g. pH/bicarbonate-based) and cohort characteristics (adults/children) could partially explain the differing findings between studies. This variability is reflected within our study by the difference in the direction of estimates across age bands, with rate increase in the 45 64 years age band, for example.

The increase in risk of DKA with deprivation levels in Scotland was highlighted by Govan et al. [29]. Shulman et al. [30] reported worse outcomes in those from lower

Table 2 Modelled estimates of the yearly fold-change in $\mathrm{HbA}_{1 \mathrm{c}}$ in the pre-package time period, and of the fold-change in $\mathrm{HbA}$ 1c following CSII initiation, compared with pre-package levels, overall and stratified by baseline $\mathrm{HbA}_{1 \mathrm{c}}$ band

\begin{tabular}{|c|c|c|c|c|c|c|}
\hline Variable & Overall & $\begin{array}{l}\text { Baseline } \mathrm{HbA}_{1 \mathrm{c}} \\
<54 \mathrm{mmol} / \mathrm{mol} \\
(<7.1 \%)\end{array}$ & $\begin{array}{l}\text { Baseline } \mathrm{HbA}_{1 \mathrm{c}} \\
54-68 \mathrm{mmol} / \\
\mathrm{mol}(7.1-8.4 \%)\end{array}$ & $\begin{array}{l}\text { Baseline } \mathrm{HbA}_{1 \mathrm{c}} \\
69-74 \mathrm{mmol} / \\
\mathrm{mol}(8.5-8.9 \%)\end{array}$ & $\begin{array}{l}\text { Baseline } \mathrm{HbA}_{1 \mathrm{c}} \\
75-84 \mathrm{mmol} / \\
\mathrm{mol}(9.0-9.8 \%)\end{array}$ & $\begin{array}{l}\text { Baseline } \mathrm{HbA}_{\mathrm{lc}} \\
>84 \mathrm{mmol} / \mathrm{mol}\end{array}$ \\
\hline Time effect, years & $1.00(0.99,1.00)$ & $0.97(0.97,0.98)$ & $0.99(0.99,1.00)$ & $1.00(0.99,1.00)$ & $1.01(1.00,1.02)$ & $1.01(0.99,1.02)$ \\
\hline \multicolumn{7}{|c|}{ CSII exposure time (ref=no CSII usage) } \\
\hline $0-1$ year & $0.88(0.87,0.89)$ & $0.99(0.95,1.02)$ & $0.91(0.89,0.92)$ & $0.89(0.86,0.91)$ & $0.82(0.79,0.84)$ & $0.79(0.76,0.83)$ \\
\hline $1-2$ years & $0.90(0.89,0.91)$ & $1.04(0.99,1.08)$ & $0.93(0.91,0.95)$ & $0.90(0.87,0.93)$ & $0.82(0.79,0.85)$ & $0.81(0.76,0.85)$ \\
\hline $2-3$ years & $0.91(0.90,0.93)$ & $1.08(1.02,1.14)$ & $0.95(0.93,0.97)$ & $0.90(0.87,0.94)$ & $0.82(0.79,0.86)$ & $0.82(0.76,0.87)$ \\
\hline $3-4$ years & $0.92(0.91,0.94)$ & $1.14(1.08,1.22)$ & $0.96(0.93,0.98)$ & $0.91(0.87,0.95)$ & $0.82(0.78,0.86)$ & $0.82(0.76,0.89)$ \\
\hline 4-5 years & $0.93(0.91,0.95)$ & $1.19(1.11,1.28)$ & $0.96(0.93,0.99)$ & $0.91(0.86,0.96)$ & $0.81(0.77,0.86)$ & $0.80(0.73,0.88)$ \\
\hline 5 or more years & $0.94(0.92,0.97)$ & $1.24(1.14,1.35)$ & $0.98(0.95,1.02)$ & $0.93(0.88,0.99)$ & $0.80(0.75,0.85)$ & $0.80(0.72,0.89)$ \\
\hline Number of observations & 23,509 & 2427 & 10,842 & 3963 & 3777 & 2500 \\
\hline Number of individuals & 4099 & 487 & 1954 & 648 & 595 & 415 \\
\hline
\end{tabular}

Data are estimates $(95 \% \mathrm{CI})$

Pre-package time period refers to 2 years prior to CSII initiation and earlier

Adjusted for sex, age and diabetes duration at CSII initiation, and baseline $\mathrm{HbA}_{1 \mathrm{c}}$ 
socioeconomic status in a Canadian paediatric study of pump users. However, our findings show that although DKA rates remain higher in more vs less deprived areas in post-pump person-time, they were generally lower in post- vs pre-pump person-time. Where differences were not significant, rates did not increase post-pump.

Since recurrent DKA is an exclusion criterion for pump therapy in Scotland, our conclusions pertain to a group of people with type 1 diabetes who have a lower pre-exposure propensity to DKA and may not generalise to those with a higher baseline DKA propensity. It is crucial to understand the mechanisms behind the observed reduction in DKA.

Several studies [1-3] have shown an association of CSII with a reduction in severe hypoglycaemia rate (a 4.34 ratereduction factor was reported by Pickup and Sutton [1]). Crude SHH rates were lower in CSII-exposed vs non-exposed person-time, and the modelled estimate was consistent with an improvement in SHH following CSII-package. However, our findings are not comparable to other studies, which captured severe hypoglycaemia events requiring third-party assistance, whereas our definition was limited to hospital admissions, missing any events treated in the community.
Strengths This is one of the largest real-world, contemporary, nationwide assessments of the prevalence of CSII and its effect on glycaemic outcomes, combining near-complete capture of data on people with type 1 diabetes nationally, long follow-up time and extensive analyses.

Limitations The main limitations of our study are the lack of data in older people, incomplete capture of self-funded flash monitoring use and non-capture of non-hospitalised severe hypoglycaemia [31]. CSIIs can be prescribed for debilitating hypoglycaemia in adults or children older than 12 , as recommended by NICE [6], but we could not evaluate hypoglycaemia as an effectiveness outcome for CSII therapy.

In Scotland, eligibility for receiving CSII on the NHS has evolved over time: from 2011 there was a major push to widen provision, and the clinical and sociodemographic profile of those receiving pumps has changed. However, the vast majority of CSII initiation occurred since 2011, with most of our data reflecting those initiating pump therapy in the period 2013-2017 and followed up to the present day (median start date 5 December 2014 [IQR 16 June 2013, 27 February 2017]). Therefore, our results reflect the contemporary profile a

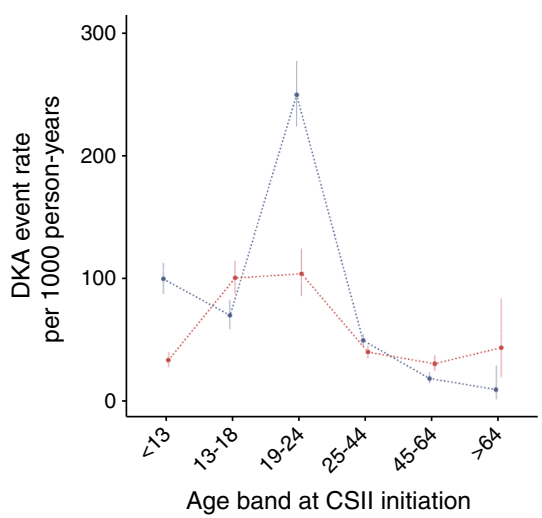

d

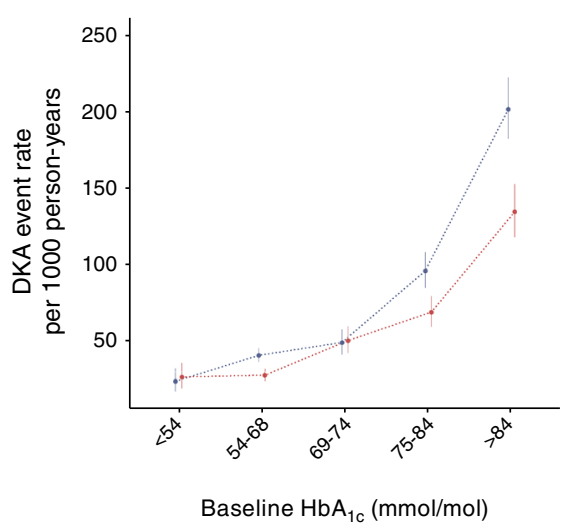

b

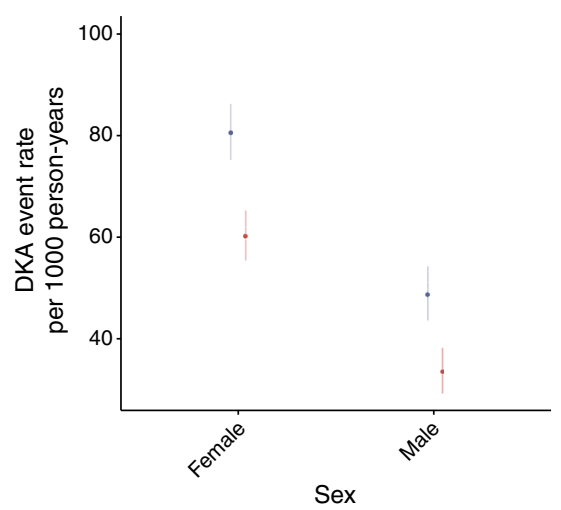

e

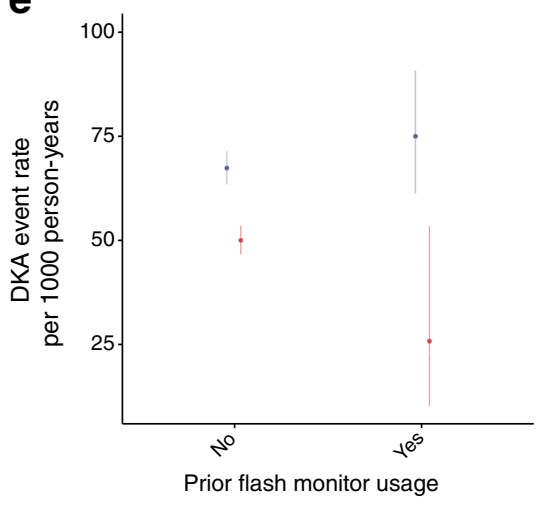

C

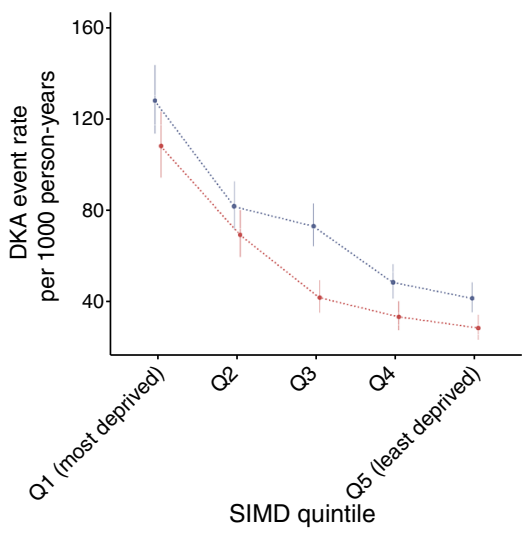

Fig. 2 Crude DKA event-rates, by CSII exposure status, stratified by (a) age band at CSII initiation, (b) sex, (c) SIMD quintile, (d) baseline HbA $1 \mathrm{c}$ band, (e) prior flash monitoring/CGM usage. Data are crude event rates (95\% CI) 
and outcomes of those in receipt of CSII therapy which is most relevant to current effectiveness and safety estimation.

The majority of CSII users had their person-time censored for start of flash monitoring/CGM. The person-time lost to follow-up was relatively low and unlikely to affect the analyses since the step-change in $\mathrm{HbA}_{1 \mathrm{c}}$ occurs within the first year post-CSII initiation.

Generalisability of findings to all people with type 1 diabetes is limited by the allocation bias resulting from the selection process for pump therapy.

Our $\mathrm{HbA}_{1 \mathrm{c}}$ analyses are susceptible to regression to the mean. However, the magnitude of pre-post change among never-users indicates that only a small proportion of the decrease observed in users following CSII initiation would actually be attributable to this artefact. Finally, as with all observational analyses, our estimates may be affected by unmeasured confounding and measurement error, although the self-controlled nature of some analyses eliminates timeinvariant confounding.

Conclusions Our study shows that CSII therapy is associated with improvements in $\mathrm{HbA}_{1 \mathrm{c}}$, DKA and SHH among pump users with type 1 diabetes in Scotland. The improvements associated with CSII therapy suggest that a more widespread use of pump therapy has the potential to reduce $\mathrm{HbA}_{1 \mathrm{c}}$ levels and DKA rates further. Our study highlights the importance of CSII technology reaching those with suboptimal glycaemic control and those from most deprived areas. This latter group, with historically poorer glycaemic control [10], stands to benefit from CSII usage, as we have not found evidence of CSII effects being worse in people from more deprived areas (in contrast to their CSII usage rates). Future research is needed to assess the effect of SIMD on outcomes in specific subgroups. Generalisation of our findings to all people with type 1 diabetes in Scotland is limited by the specific eligibility criteria to CSII. Hence, it is crucial to identify the determinants of good response to CSII to optimise a targeted wider roll-out. Moreover, other outcomes that we cannot directly quantify need to be considered, such as improvement in quality of life and reduction in glucose variability. Motivation is critical to successful CSII usage [23], and it would be interesting to examine how outcomes differ in a known-to-be-motivated group (pregnant women). Finally, future research is warranted to examine how the rapid evolution of technology (integrated pump-and-CGM systems with alarms and/or suspension systems, hybrid/DIY closed loops) affects DKA and severe hypoglycaemia rates.

Supplementary Information The online version contains peer-reviewed but unedited supplementary material available at https://doi.org/10.1007/ s00125-021-05413-7.

Acknowledgements We thank the SDRN Epidemiology Group: J. Chalmers (Diabetes Centre, Victoria Hospital, Kirkcaldy, UK), C.
Fischbacher (Information Services Division, NHS National Services Scotland, Edinburgh, UK), B. Kennon (Queen Elizabeth University Hospital, Glasgow, UK), G. Leese (Ninewells Hospital, Dundee, UK), R. Lindsay (British Heart Foundation Glasgow Cardiovascular Research Centre, University of Glasgow, Glasgow, UK), J. McKnight (Western General Hospital, NHS Lothian, Edinburgh, UK), J. Petrie (Institute of Cardiovascular \& Medical Sciences, University of Glasgow, Glasgow, UK), R. McCrimmon (Division of Molecular and Clinical Medicine, University of Dundee, Dundee, UK), S. Philip (Grampian Diabetes Research Unit, Diabetes Centre, Aberdeen Royal Infirmary, Aberdeen, UK), D. McAllister (Institute of Health \& Wellbeing, University of Glasgow, Glasgow, UK), E. Pearson (Population Health and Genomics, School of Medicine, University of Dundee, Dundee, UK) and S. Wild (Usher Institute, University of Edinburgh, Edinburgh, UK).

Some of the data were presented as an abstract (poster presentation) at the 56th EASD Annual Meeting in 2020.

Data availability We do not have governance permissions to share individual-level data on which these analyses were conducted. However, for any genuine requests to audit the validity of the analyses, the verifiable research pipeline that we operate allows researchers to make a request to the corresponding author to view the analyses being run and the resulting tabulations, summary statistics and parameter estimates.

Funding This study was supported by funding from Diabetes UK (17/ 0005627) and the Chief Scientist Office (ref. ETM/47).

Authors' relationship and activities All authors have completed and submitted the ICMJE Form for Disclosure of Potential Conflicts of Interest. JAM reports personal fees from Napp pharmaceuticals, institutional fees for trial participation from Novo Nordisk, Eli Lilly, Boehringer, MedImmune Ltd. and GlaxoSmithKline, during the conduct of this study. TMC is a Diabetes UK 'Sir George Alberti Clinical Research Fellow' and reports grant no.18/0005786 from Diabetes UK, outside the submitted work. SHW reports meeting attendance supported by Novo Nordisk, outside the submitted work. RJM reports personal fees from Sanofi and Novo Nordisk, outside the submitted work. JP reports personal fees from Merck KGaA, Novo Nordisk and Boehringer Ingelheim, non-financial support from Merck $\mathrm{KGaA}$, Astra Zeneca and Janssen Pharmaceuticals, outside the submitted work. RSL reports being an advisory board member for and receiving speaker fees from Eli Lilly, Servier and Novo Nordisk, outside the submitted work. NS reports personal fees from Amgen, Astra Zeneca, Eli Lilly, Merck Sharp \& Dohme, Novartis, Novo Nordisk, Pfizer and Sanofi, grants and personal fees from Boehringer Ingelheim, outside the submitted work. HMC reports grants and personal fees from Eli Lilly and Company, during the conduct of the study; grants and personal fees from Novo Nordisk, grants from AstraZeneca LP, Regeneron, and Pfizer, institutional fees from Novartis Pharmaceuticals and Sanofi Aventis, and being a shareholder with Roche Pharmaceuticals, outside the submitted work. No other disclosures were reported.

Contribution statement AJ, JAM, FWG, HMC and PMM conceived and designed the analyses. AJ performed the analyses. AJ and HMC drafted the initial manuscript. SJM, LAKB and SH were involved in the cleaning, harmonisation, quality-control and databasing of data and contributed to critical revision of the manuscript. BK, JAM, RJM, GL, RSL, JP, JC, SP, SHW and NS contributed to data acquisition and critical revision of the manuscript. FWG and JAM were involved in interpretation of the data and critically revising and editing the manuscript. PMM was involved in critical revision of the manuscript. JEOR, TMC and AH were involved in the interpretation of the data and critically revising and editing the manuscript. $\mathrm{HMC}$ is the guarantor and, as such, is responsible for the integrity of the work as a whole. All authors approved the manuscript for publication. 
Open Access This article is licensed under a Creative Commons Attribution 4.0 International License, which permits use, sharing, adaptation, distribution and reproduction in any medium or format, as long as you give appropriate credit to the original author(s) and the source, provide a link to the Creative Commons licence, and indicate if changes were made. The images or other third party material in this article are included in the article's Creative Commons licence, unless indicated otherwise in a credit line to the material. If material is not included in the article's Creative Commons licence and your intended use is not permitted by statutory regulation or exceeds the permitted use, you will need to obtain permission directly from the copyright holder. To view a copy of this licence, visit http://creativecommons.org/licenses/by/4.0/.

\section{References}

1. Pickup J, Sutton A (2008) Severe hypoglycaemia and glycaemic control in type 1 diabetes: meta-analysis of multiple daily insulin injections compared with continuous subcutaneous insulin infusion. Diabet Med 25(7):765-774. https://doi.org/10.1111/j.14645491.2008.02486.x

2. Johnson SR, Cooper MN, Jones TW, Davis EA (2013) Long-term outcome of insulin pump therapy in children with type 1 diabetes assessed in a large population-based case-control study. Diabetologia 56(11):2392-2400. https://doi.org/10.1007/s00125013-3007-9

3. Karges B, Schwandt A, Heidtmann B et al (2017) Association of insulin pump therapy vs insulin injection therapy with severe hypoglycemia, ketoacidosis, and glycemic control among children, adolescents, and young adults with type 1 diabetes. JAMA 318(14):1358-1366. https://doi.org/10.1001/jama.2017.13994

4. Scrimgeour L, Cobry E, McFann K et al (2007) Improved glycemic control after long-term insulin pump use in pediatric patients with type 1 diabetes. Diabetes Technol Ther 9(5):421-428. https://doi. org/10.1089/dia.2007.0214

5. Sherr JL, Hermann JM, Campbell F et al (2016) Use of insulin pump therapy in children and adolescents with type 1 diabetes and its impact on metabolic control: comparison of results from three large, transatlantic paediatric registries. Diabetologia 59(1): 87-91. https://doi.org/10.1007/s00125-015-3790-6

6. National Institute for Health and Care Excellence (2008) Continuous subcutaneous insulin infusion for the treatment of diabetes mellitus. Technology appraisal guidance [TA151]. NICE, London

7. McKnight JA, Ochs A, Mair C et al (2019) The effect of DAFNE education, continuous subcutaneous insulin infusion, or both in a population with type 1 diabetes in Scotland. Diabet Med 37(6): 1016-1022

8. Livingstone SJ, Looker HC, Hothersall EJ et al (2012) Risk of cardiovascular disease and total mortality in adults with type 1 diabetes: Scottish registry linkage study. PLoS Med 9(10). https:// doi.org/10.1353/bhm.2012.0071

9. Anwar H, Fischbacher C, Leese G et al (2011) Assessment of the under-reporting of diabetes in hospital admission data: a study from the Scottish Diabetes Research Network Epidemiology Group. Diabet Med 28(12):1514-1519. https://doi.org/10.1111/j.14645491.2011.03432.x

10. Mair C, Wulaningsih W, Jeyam A et al (2019) Glycaemic control trends in people with type 1 diabetes in Scotland 2004-2016. Diabetologia 62(8):1375-1384. https://doi.org/10.1007/s00125019-4900-7

11. Clements MA, Foster NC, Maahs DM et al (2016) Hemoglobin $\mathrm{A} 1 \mathrm{c}(\mathrm{HbA1} \mathrm{c})$ changes over time among adolescent and young adult participants in the T1D exchange clinic registry. Pediatr Diabetes 17(5):327-336. https://doi.org/10.1111/pedi.12295
12. R Core Team (2019) R: a language and environment for statistical computing. R Foundation for Statistical Computing, Vienna, Austria

13. McGurnaghan SJ, Brierley L, Caparrotta TM et al (2019) The effect of dapagliflozin on glycaemic control and other cardiovascular disease risk factors in type 2 diabetes mellitus: a real-world observational study. Diabetologia 62(4):621-632. https://doi.org/10. 1007/s00125-018-4806-9

14. Singer JD, Willett JB (2003) Applied longitudinal data analysis: modeling change and event occurrence. Oxford University Press, New York

15. Pinheiro J, Bates D, DebRoy S, Sarkar D, R Core Team (2019) nlme: Linear and Nonlinear Mixed Effects Models. R package version 3.1-151, https://CRAN.R-project.org/package=nlme

16. Berchialla P, Baldi I, Notaro V, Barone-Monfrin S, Bassi F, Gregori D (2009) Flexibility of Bayesian generalized linear mixed models for oral health research. Stat Med 28(28):3509-3522. https://doi. org $/ 10.1002 / \operatorname{sim} .3648$

17. Stevens GA, Bennett JE, Hennocq Q et al (2015) Trends and mortality effects of vitamin A deficiency in children in 138 lowincome and middle-income countries between 1991 and 2013: a pooled analysis of population-based surveys. Lancet Glob Health 3(9):e528-e536. https://doi.org/10.1016/S2214-109X(15)00039-X

18. van den Boom L, Karges B, Auzanneau M et al (2019) Temporal trends and contemporary use of insulin pump therapy and glucose monitoring among children, adolescents, and adults with type 1 diabetes between 1995 and 2017. Diabetes Care 42(11):2050-2056

19. Health and Social Care Information Centre (2019) National Diabetes Audit - Insulin Pump Report 2017-18. Available from: https://digital.nhs.uk/data-and-information/publications/statistical/ national-diabetes-audit/national-diabetes-audit\%2D\%2D-insulinpump-report-2017-18. Accessed 14 Dec 2020

20. Scott A, O'Cathain A, Goyder E (2019) Socioeconomic disparities in access to intensive insulin regimens for adults with type 1 diabetes: a qualitative study of patient and healthcare professional perspectives. Int J Equity Health 18(1):1-13

21. Beato-Vibora P, Yeoh E, Rogers H, Hopkins D, Amiel S, Choudhary P (2015) Sustained benefit of continuous subcutaneous insulin infusion on glycaemic control and hypoglycaemia in adults with type 1 diabetes. Diabet Med 32(11):1453-1459. https://doi. org/10.1111/dme.12869

22. Anyanwagu U, Olaoye H, Jennings P et al (2017) Continuous subcutaneous insulin infusion (CSII) therapy at Derby Teaching Hospitals: sustained benefits in glucose control. Diabet Med 34(8):1154-1157. https://doi.org/10.1111/dme.13367

23. Pickup JC (2019) Is insulin pump therapy effective in type 1 diabetes? Diabet Med 36(3):269-278. https://doi.org/10.1111/dme. 13793

24. Mehta SN, Andersen HU, Abrahamson MJ et al (2017) Changes in $\mathrm{HbAlc}$ and weight following transition to continuous subcutaneous insulin infusion therapy in adults with type 1 diabetes. J Diabetes Sci Technol 11(1):83-86. https://doi.org/10.1177/ 1932296816658900

25. Weissberg-Benchell J, Antisdel-Lomaglio J, Seshadri R (2003) Insulin pump therapy: a meta-analysis. Diabetes Care 26(4): 1079-1087. https://doi.org/10.2337/diacare.26.4.1079

26. Pickup J, Keen H (2002) Continuous subcutaneous insulin infusion at 25 years: evidence base for the expanding use of insulin pump therapy in type 1 diabetes. Diabetes Care 25(3):593-598. https:// doi.org/10.2337/diacare.25.3.593

27. Hanas R, Ludvigsson J (2006) Hypoglycemia and ketoacidosis with insulin pump therapy in children and adolescents. Pediatr Diabetes 7:32-38. https://doi.org/10.1111/j.1399-543X.2006. 00169.x

28. Thomas M, Harjutsalo V, Feodoroff M, Forsblom C, Gordin D, Groop P-H (2020) The long-term incidence of hospitalization for 
ketoacidosis in adults with established T1D -a prospective cohort study. J Clin Endocrinol Metab 105(1):dgz003

29. Govan L, Maietti E, Torsney B et al (2012) The effect of deprivation and $\mathrm{HbA} 1 \mathrm{c}$ on admission to hospital for diabetic ketoacidosis in type 1 diabetes. Diabetologia 55(9):2356-2360. https://doi.org/ 10.1007/s00125-012-2601-6

30. Shulman R, Stukel TA, Miller FA et al (2016) Low socioeconomic status is associated with adverse events in children and teens on insulin pumps under a universal access program: a populationbased cohort study. BMJ Open Diabetes Res Care 4(1):e000239. https://doi.org/10.1136/bmjdrc-2016-000239
31. McCoy RG, Lipska KJ, Van Houten HK, Shah ND (2020) Association of cumulative multimorbidity, glycemic control, and medication use with hypoglycemia-related emergency department visits and hospitalizations among adults with diabetes. JAMA Netw Open 3(1):e1919099-e1919099. https://doi.org/10.1001/ jamanetworkopen.2019.19099

Publisher's note Springer Nature remains neutral with regard to jurisdictional claims in published maps and institutional affiliations. 